\title{
Checkpoint Inhibitors in the First-Line Setting in Advanced Non-Small Cell Lung Cancer: A Meta-Analysis
}

\begin{abstract}
Keywords: Lung cancer; Non-small Cell; Immunotherapy Checkpoint inhibitor

Abstract

Background: While the standard first-line therapy for patients with advanced Non-Small-Cell Lung Cancer (NSCLC) without targetable genetic aberrations is platinum-based chemotherapy (CTX), recently, inhibitors of Programmed Cell Death-1 (PD-1) or its Legend (PD-L1) have set a novel option for such patients. To quantify the overall efficacy of those agents - here Called Checkpoint Inhibitors (CPIs) - and in patient subgroups, this meta-analysis was performed.
\end{abstract}

Methods: Using a defined selection criterion, a literature search identified 12 Randomized Clinical Trials (RCTs) involving 7,095 patients where CPIs have been used in the first-line setting.

Results: In five RCTs, CPIs were compared against CTX, a comparable progression-free survival was observed (hazard ratio [HR] $=0.88 ; 95 \% \mathrm{Cl}, 0.77-1.01 ; \mathrm{P}=0.06)$, with a significant $21 \%$ decreased in mortality $(\mathrm{HR}=0.79(95 \% \mathrm{Cl}, 0.71-0.87) ; \mathrm{P}=<0.0001)$. Improved overall survival was attained across all relevant patient subgroups. In the remaining seven RCTs examining CPIs plus CTX versus CTX alone, the combined regimens reduced progression and deaths by $39 \%(\mathrm{HR}=$ $0.61: 95 \% \mathrm{Cl} 0.57-0.66 \% \mathrm{P}<0.0001)$, and $26 \%(\mathrm{HR}=0.74: 95 \% \mathrm{Cl}, 0.63$ 0.88; $\mathrm{P}<0.0001$ ), respectively. CPIs plus CTX versus CTX alone doubled the objective response rate. Patients with high PD-Ll expression consistently achieved the highest benefit, although some patients with low expression have also benefited. Number of patients in included studies, male gender proportion, PD-L1 expression, and median duration of follow-up were the variables that explained heterogeneity in the pooled outcome.

Conclusion: Current evidence indicates significant efficacy with the use of CPIs mostly in combination with CTX as the first-line therapy in NSCLC without targetable agents. Besides the levels of PD-LI expression, identifying additional predicting biomarkers is needed.

\section{Introduction}

Lung cancer is the most commonly occurring cancer in men and the third commonest cancer in women. In 2018 an estimated 2 million new lung cancer cases are diagnosed in both sexes combined representing $11.6 \%$ of total cases worldwide. In the same year, lung cancer was the leading cause of cancer death $(18.4 \%$ of the total cancer deaths) [1].

Until recently and despite the major progress in understanding the molecular pathways of non-small cell lung cancer (NSCLC), only few effective therapeutic options were available for most patients with metastatic disease without targetable agents with a dismal survival of only $4 \%[1]$

Activation of the Programmed Death cell-1 (PD-1) pathway is an inhibitory mechanism that tumors may exploit to escape the immunosurveillance. Inhibition of the PD-1 pathway using PD-1

\section{Journal of}

\section{Cancer Sciences}

Ibrahim EM ${ }^{1 *}$, Refae AA ${ }^{1}$, Bayer AM${ }^{1}$, Al-Masri OA ${ }^{1}$, Eldahna WM'1 ${ }^{1}$ Al-Foheidi $\mathrm{ME}^{2}$ and Al-Mansour $\mathbf{M M}^{2}$ IInternational Medical Center, Kingdom of Saudi Arabia

${ }^{2}$ Princess Noorah Oncology Center, King Abdulaziz Medical City, Kingdom of Saudi Arabia

\section{*Address for Correspondence}

Ibrahim EM, Professor of Medicine \& Oncology Director, Oncology Center, International Medical Center, PO Box 2172, Jeddah 21451 Kingdom of Saudi Arabia, Phone: +966505-82-5953, Fax: +966521-6509141; E-mail: ezzibrahim@imc.med.sa

Submission: 30 September, 2019

Accepted: 28 October, 2019

Published: 04 November, 2019

Copyright: ๑ 2019 Ibrahim EM, et al. This is an open access article distributed under the Creative Commons Attribution License, which permits unrestricted use, distribution, and reproduction in any medium, provided the original work is properly cited.

or programmed death legend-1 (PD-L1) inhibitors or Checkpoint inhibitors (CPIs) has transformed the treatment of metastatic NSCLC [2]. Recently, several CPIs agents were approved for clinical use. For metastatic/advanced NSCLC, nivolumab and atezolizumab are approved for treating patients whose disease progressed during or after platinum-based chemotherapy (CTX) irrespective of PD-L1 expression level, whereas pembrolizumab is approved as monotherapy for previously untreated patients with PD-L1 levels greater $\geq 50 \%$, previously treated with PD-L1 levels $\geq 1 \%$, and regardless of PDL1 expression in combination with platinum and pemetrexed in nonsquamous NSCLC (https://www.fda.gov/). On the other hand, durvalumab is only approved for the treatment of unresectable stage III NSCLC which has not progressed following concurrent platinumbased chemotherapy and radiation therapy.

To quantify the efficacy and safety of CPIs several meta-analyses and systematic reviews have been published. Lee et al. assessed the role of CPIs in previously treated patients in EGFR mutated advanced NSCLC [3]. In that meta-analysis of three studies, there were there were no reported data concerning heterogeneity of the pooled effects. In a systematic review and network meta-analysis, Créquit et al. analyzed the efficacy and safety of second-line treatments of advanced NSCLC but they included CPIs and other targeted therapies [4]. The meta-analysis reported by Ramos-Esquivel et al. compared CPIs versus docetaxel for previously treated patients [5]. In another review, Ryu et al. examined the role of atezolizumab for the first-line treatment of NSCLC [6]. However, in the latter review only results of five studies were available and the agent was tested in diverse clinical settings (as monotherapy, in combination with chemotherapy; in neoadjuvant/adjuvant setting; in combination with bevacizumab; and in combination with radiation or chemoradiation), moreover, no pooled outcomes were reported.

Therefore, in the current meta-analysis we intended to examine the efficacy of CPIs versus chemotherapy (CTX) and the combination of CPIs plus CTX versus CTX alone restricted to the first-line for advanced/metastatic NSCLC. The lack of reported data concerning heterogeneity in the effect size estimates or the influence of potential covariates on such heterogeneity provided an additional impetus to carry out the current analysis. 


\section{Materials and Methods}

\section{Search strategy}

Between January 2005 and April 2019, we identified studies of interest by first conducting an electronic literature search of the following databases: MEDLINE, EMBASE, and the Cochrane Library. We also searched for relevant abstracts in conference proceedings of the American Society of Clinical Oncology, and the European Society for Medical Oncology.

We used Medical Subject Heading terms or Keywords: "lung", "cancer OR neoplasm OR tumor OR carcinoma OR malignant", "non-small cell, "therapy OR treatment", "metastatic or advanced", "immunotherapy OR checkpoint inhibitor OR checkpoint inhibitors (CPIs), OR nivolumab OR pembrolizumab OR atezolizumab OR durvalumab", "clinical trial (mh) OR controlled clinical trial (mh) OR randomized controlled clinical trial ) $\mathrm{mh}$ (", "comparative study (mh) OR prospective study (mh) OR evaluation study (mh) OR follow-up study (mh). And the search terms were combined with the Keywords "first line OR previously untreated OR naïve patients".

\section{Selection criteria}

We included all studies that met the following criteria: (1) published in English language between January 2005 and April 2019; (2) included patients of any age or gender with metastatic or advanced NSCLC; (3) investigated the efficacy of CPIs in the first-line setting (chemotherapy (CTX) and immunotherapy/CPIs naive for metastatic disease) either used as monotherapies or in combination with CTX; (4) randomized control studies either phase II or III; (5) reported hazard ratio (HR) for disease-free survival (DFS) or overall survival (OS), and/or odds ratio (OR) for objective response rate (ORR), or reported adequate data allowing the outcome measures to be computed; and (6) published as original articles or abstracts (no case reports, case series, reviews, comments, letters, or editorials). When two or more articles reported duplicate data, we included only the most recent data, the study with the longer follow-up, or the most relevant study. However, we included studies that have used the same data set but examined additional relevant outcomes.

\section{Data extraction}

Three authors (EMI, AAR, AMB) independently inspected each item identified by the search and applied the inclusion/exclusion criteria. All authors reviewed the articles and discussed the data intended for extraction. Extracted data included the following fields: the study name, first author's last name, publication year, study description, study design, CPI used, number of patients, gender, median age, ECOG status, smoking history, histology, median follow-up, and outcome measures including results reported for patient subgroups.

\section{Outcome measures}

The outcome measures extracted or computed were the HR for PFS and/or OS and the OR for the ORR. Also extracted was the 95\% Confidence Interval (CI) for each outcome measure. PFS was defined as the time from randomization to disease progression or death from any cause, while OS was defined as the time from random assignment to death from any cause. ORR was defined as the sum of complete and partial response rates.

\section{Statistical analyses}

The pooled estimates of the HR and OR and the CI were the primary end points of the meta-analysis. We calculated unreported outcome measure and its $95 \%$ CI using the procedure proposed by Tierney et al. [7], which is based on the method reported by Parmar et al. [8]. Where appropriate, we also used the built-in calculator of the Review Manager for Windows software version 5.2.3 to compute pertinent data (The Cochrane Collaboration, Oxford, UK). In studies that reported a univariate and a multivariate analysis for the same comparison, we only used the latter.

We assessed the heterogeneity of the results by inspecting the graphical presentations and by calculating a $\mathrm{X}^{2}$ test of heterogeneity and the $I^{2}$ statistic of inconsistency $[9,10]$. Statistically significant heterogeneity was defined as a $\mathrm{X}^{2} \mathrm{P}$ value less than 0.1 or an $I^{2}$ statistic greater than $50 \%$. The pooled estimates of HR or and the associated 95\% CI were obtained using the DerSimonian and Laird randomeffects model [11]. The latter model was used rather than the fixedeffects procedure due to the various designs and agents used in the included studies.

We performed meta-regression analysis to determine to what extent the effects of clinical variables could explain any demonstrated heterogeneity in the pooled estimates of PFS or OS. The dependent variable was the $\operatorname{lnHR}$ weighted for the inverse of variance to perform weighted least-square linear regression. We first conducted a univariate regression analysis for each relevant variable followed by a multivariate regression analysis including only variables found significant in the univariate analysis. The tested variables were patients' numbers, median age, proportion of male patients, Eastern Cooperative Oncology Group (ECOG) performance status, smoking history, histology, PD-L1 expression score, and median follow-up. In the meta-regression analyses, we assumed the data to be missing at random; therefore, observed study characteristics were used to impute missing data by means of multiple imputations [12].

We also performed subgroup analyses to assess the potential contributions of various variables to the main outcome. We excluded studies that did not provide enough data to permit estimating relevant parameters in subgroup analyses.

A funnel plot estimating the precision of trials (plots of logarithm of the HR against its inverse standard error) was examined for asymmetry to determine publication bias [13]. Because of the small number of included studies, we used the fail-safe $\mathrm{N}$ [14], and the trim and fill methods to quantify publication bias [15]. The first method determines how many missing studies needed to be incorporated in the analysis before the $\mathrm{P}$ value becomes non-significant. While the latter gives the approximate number of studies to be imputed to make the funnel plot symmetric.

All statistical tests were two-sided. We used Comprehensive Meta-analysis (Biostat, version 3.3.070, Englewood New Jersey, USA) and Review Manager for all pooled estimates. For metaregression analyses and assessment of publication bias, we used the Comprehensive Meta-analysis software.

\section{Results}

We identified 3711 potentially relevant articles (Figure 1). 
Citation: Ibrahim EM, Refae AA, Bayer AM, Al-Masri OA, Eldahna WM, et al. Checkpoint Inhibitors in the First-Line Setting in Advanced Non-Small Cell Lung Cancer: A Meta-AnalysisJ Cancer Sci. 2019;6(1): 14.

After exclusion of duplicate references, non-relevant literature, and those that did not satisfy the inclusion criteria, 12 candidate articles were included [16-28]. There were 7,095 patients in the included studies, 3,832 (54\%), and 3,263 (46\%) patients were allocated to in the CPIS and control arms, respectively. The median age (95\% CI) was 64.0 (63.5-66.0), and 65.0 (63.7-65.1) years, while male gender constituted $65 \%$ versus and $63 \%$ in patients in the CPIs and control arms, respectively. Sixty-three and $62 \%$ of the patients presented with ECOG $\geq 2$ in the CPIs and control arms, respectively.

\section{Brief description of the included studies}

Table 1 depicts the patients and disease characteristics of the 12 studies, and Table 2 summaries the outcome measures of those studies and outcomes according to PD-L1 expression. Four studies compared atezolizumab in combination with chemotherapy (CTX) versus CTX alone $(17,18,25,26)$, and in a fifth study, nivolumab was used as a monotherapy versus CTX (16). In the sixth study (CheckMate-277), nivolumab was used in combination with ipilimumab (anti-cytotoxic T-lymphocyte antigen 4) against CTX (27). In the latter study, a third arm of nivolumab monotherapy was also included. In all three arms, the investigators explored the efficacy of nivolumab with or without ipilimumab among patients with high tumor mutational burden (TMB; $\geq 10$ mutations or $\geq 13$ per megabase).

Pembrolizumab in combination with CTX versus CTX alone was tested in three studies [19-21], while in two studies (KeyNote-024 and KeyNote-042), pembrolizumab was used as a monotherapy versus CTX $[23,24,28]$. In the KeyNote-024, only patients with PDL1 expression $\geq 50 \%$ were included. Finally, the we included a study that compared drvalumab with or without tremelimumab against CTX [22].

Of all the included studies, only two allowed a few patients with EGFR/ALK aberrations. In the IMpower-131, though testing

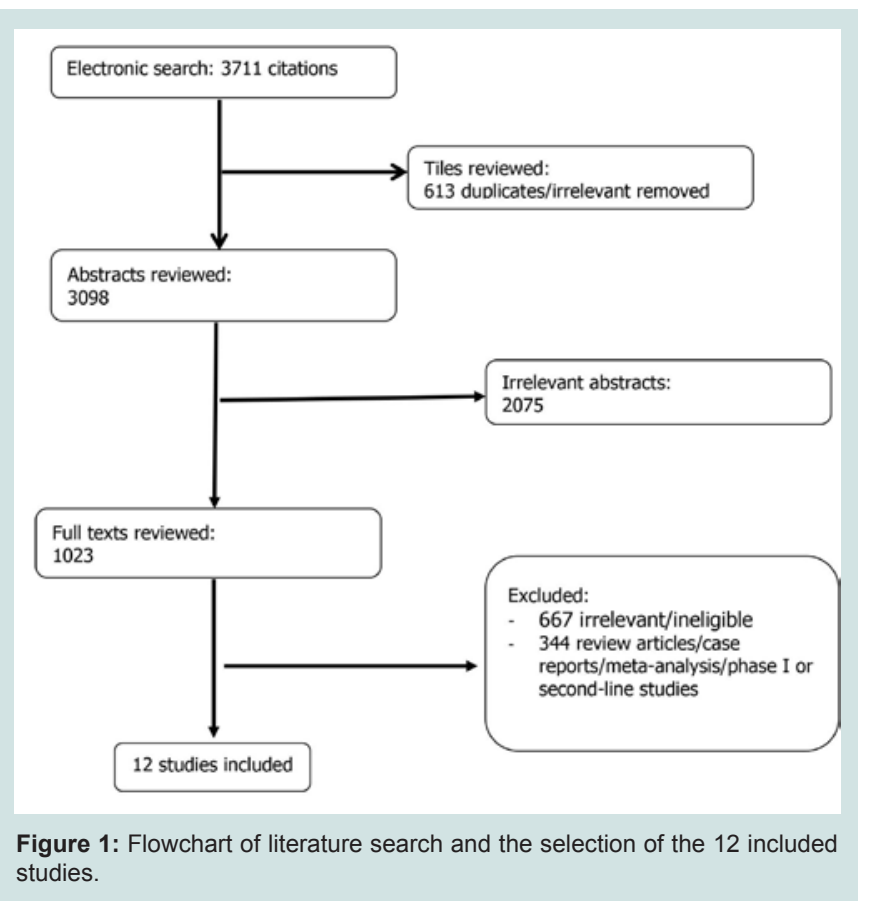

for EGFR mutation or ALK translocation was not mandatory, patients with a sensitizing mutation must have disease progression or intolerance to treatment with $\geq 1$ approved targeted therapy to included, however, their number was not reported [18]. In the second study (IMpower-150) [26], approximately $20 \%$ of patients had EGFR/ ALK mutations in each of the experimental or control arm.

Of the 12 studies, four studies only included patients with nonsquamous NSCLC $[17,19,20,25,26]$, while in two trials only patients with squamous NSCLC were allowed [18,21]. In the remaining fife studies patients with either squamous or nonsquamous histology were eligible $[16,23,24,27,28]$.

In this meta-analysis, we defined a cohort where CPIs were compared against CTX. This set consisted of five studies (CheckMate-026 [16], MYSTIC [22], KeyNote-024 [23,24], CheckMate-227 [27], and KeyNote-042 [28]), that comprised 3,057 patients (961 [52\%], and 1,459 [48\%] patients in the CPIs and CTX arms, respectively).

The second data cohort included the remaining seven studies where CPIs plus CTX were compared against CTX alone (IMpower-130 [17], IMpower-131 [18], KeyNote-021 [19], KeyNote-189 [20], KeyNote-407 [21], IMpower-132 [25], and IMpower-150 [26]). In this cohort there were 4,038 patients $(2,234$ [55\%], and 1,804 [45\%] in the CPIs plus CTX, and CTX only arms, respectively).

\section{CPIs as Monotherapy versus CTX}

\section{Analysis of PFS}

In studies reported median follow-up, the average was 13.2 months. Figure 2 shows that CPIs produced a numerically, though not significant benefit on PFS as compared with CTX $(\mathrm{HR}=0.88$; 95\% CI, 0.77-1.01; $\mathrm{P}=0.06)$. The analysis, however, showed significant model heterogeneity $\left(I^{2}=74 \%\right)$. Included in that analysis, were reported data regardless of the PD-L1 level of expression.

Meta-regression analysis was performed to identify covariates that would explain model heterogeneity. Tested in the analysis were defined in the methodology section. The meta-regression analysis identified the total number of patients and the proportion of male gender in the experimental arms were the only variables that explained $81 \%$ of the variance in effect size (Table 3 ). Patients number and proportion of male were positively associated with HR suggesting lesser benefit with increasing proportion of male gender and larger study population.

Although a non-significant trend favored CPIs in all subgroups except smoking history, the analysis didn't show a favorable benefit of CPIs compared with CTX on PFS irrespective of patients age, gender, ECOG status, smoking history, histology, or tumor proportion score of PD-L1 (Figure 3). On the other hand, the patients with high TMB attained a significant benefit from CPIs (HR $=0.68$; 95\% CI, 0.500.91). On the contrary, CPIs benefit was equal to CTX among the patients whose tumor expressed low/medium TMB (HR $=1.38$; 95\% CI, 0.82-2.31), however, that comparison was associated with heterogeneity $\left(I^{2}=82 \%\right)$.

\section{Analysis of OS}

Figure 4 demonstrates the pooled analysis of OS of the five studies 
Citation: Ibrahim EM, Refae AA, Bayer AM, Al-Masri OA, Eldahna WM, et al. Checkpoint Inhibitors in the First-Line Setting in Advanced Non-Small Cell Lung Cancer: A Meta-AnalysisJ Cancer Sci. 2019;6(1): 14.

ISSN: 2377-9292

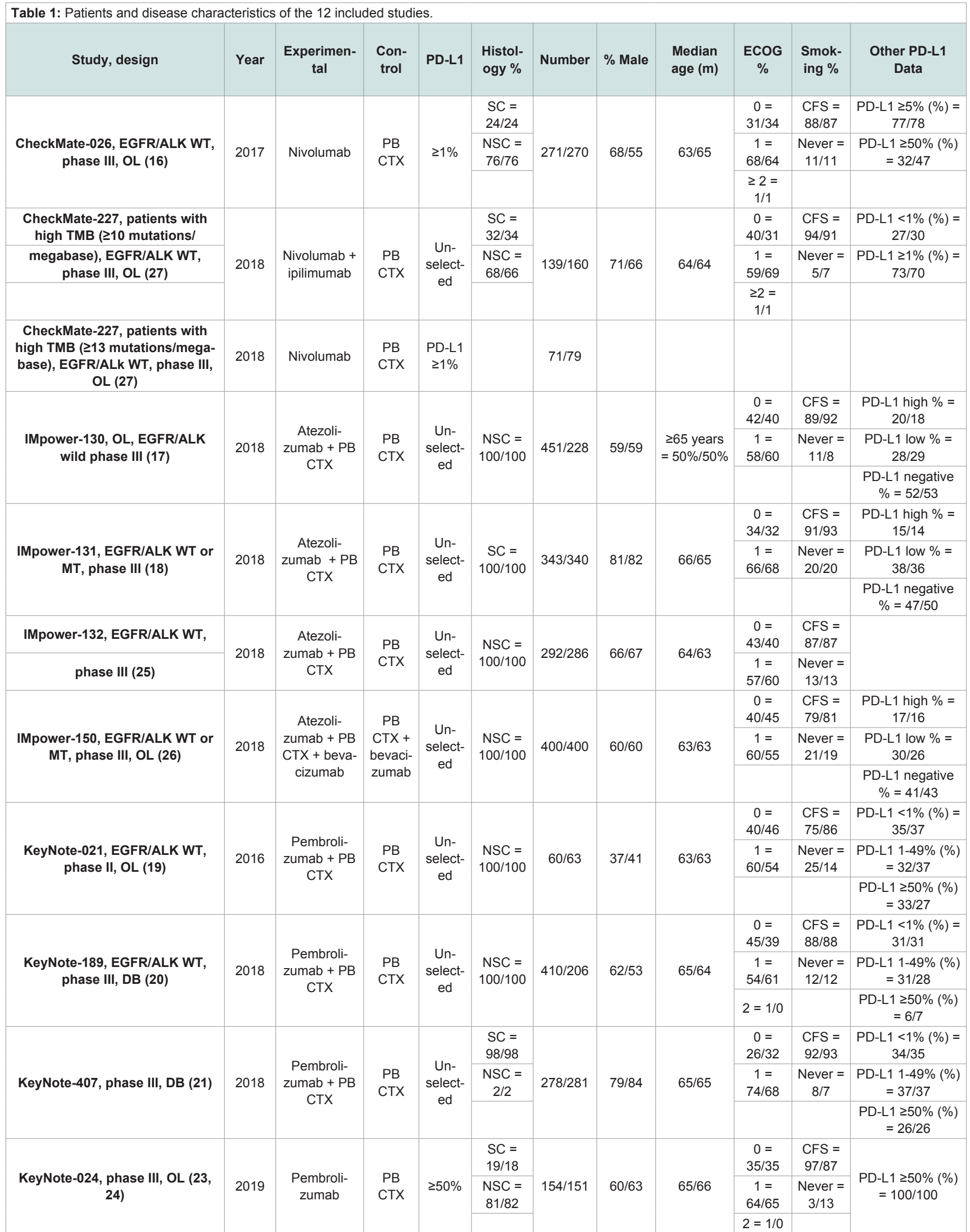


Citation: Ibrahim EM, Refae AA, Bayer AM, Al-Masri OA, Eldahna WM, et al. Checkpoint Inhibitors in the First-Line Setting in Advanced Non-Small Cell Lung Cancer: A Meta-AnalysisJ Cancer Sci. 2019;6(1): 14.

ISSN: 2377-9292

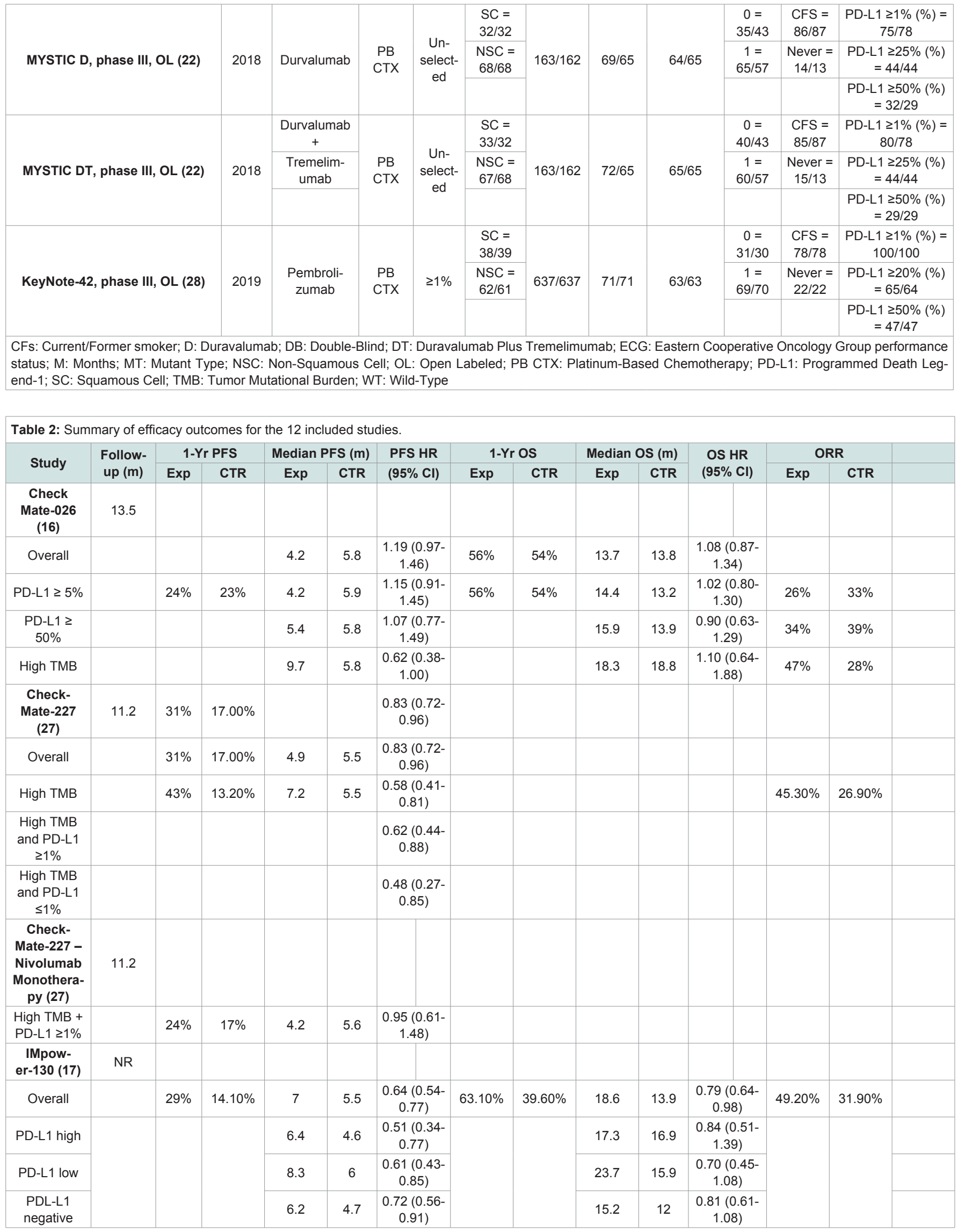


Citation: Ibrahim EM, Refae AA, Bayer AM, Al-Masri OA, Eldahna WM, et al. Checkpoint Inhibitors in the First-Line Setting in Advanced Non-Small Cell Lung Cancer: A Meta-AnalysisJ Cancer Sci. 2019;6(1): 14

ISSN: $2377-9292$

\begin{tabular}{|c|c|c|c|c|c|c|c|c|c|c|c|c|c|c|c|c|}
\hline $\begin{array}{c}\text { IMpow- } \\
\text { er-131 (18) }\end{array}$ & 12.8 & & & & & & & & & & & & & & & \\
\hline Overall & & $25 \%$ & $12.00 \%$ & 6.3 & 5.6 & \multicolumn{2}{|c|}{$\begin{array}{c}0.71(0.60- \\
0.85)\end{array}$} & $55.60 \%$ & $56.90 \%$ & 14 & 13.9 & \multicolumn{2}{|c|}{$\begin{array}{c}0.96(0.78- \\
1.18)\end{array}$} & $49 \%$ & $41 \%$ & \\
\hline PD-L1 high & & $48 \%$ & $20 \%$ & 10.1 & 5.5 & \multicolumn{2}{|c|}{$\begin{array}{c}0.44(0.27- \\
0.71)\end{array}$} & $67 \%$ & $52 \%$ & 23.6 & 14.1 & \multicolumn{2}{|c|}{$\begin{array}{c}0.56(0.32- \\
0.99)\end{array}$} & $60 \%$ & $33 \%$ & \\
\hline PD-L1 low & & $20 \%$ & $9 \%$ & 6 & 5.6 & \multicolumn{2}{|c|}{$\begin{array}{c}0.70(0.53- \\
0.92)\end{array}$} & $54 \%$ & $64 \%$ & 12.4 & 16.6 & \multicolumn{2}{|c|}{$\begin{array}{c}1.34(0.95- \\
1.90)\end{array}$} & $52 \%$ & $44 \%$ & \\
\hline $\begin{array}{c}\text { IMpow- } \\
\text { er-132 (25) }\end{array}$ & 14.8 & & & & & & & & & & & & & & & \\
\hline Overall & & $34 \%$ & $17 \%$ & 7.6 & 5.2 & \multicolumn{2}{|c|}{$\begin{array}{c}0.60(0.49- \\
0.72) \\
\end{array}$} & $59.60 \%$ & $55.40 \%$ & 18.1 & 13.6 & \multicolumn{2}{|c|}{$\begin{array}{c}0.81(0.64- \\
1.03)\end{array}$} & NR & NR & \\
\hline $\begin{array}{c}\text { IMpow- } \\
\text { er-150 (26) }\end{array}$ & 15.4 & & & & & & & & & & & & & & & \\
\hline Overall & & $37 \%$ & $18.60 \%$ & 8.3 & 6.8 & \multicolumn{2}{|c|}{$\begin{array}{c}0.61(0.52- \\
0.72)\end{array}$} & & & & & & & & & \\
\hline $\begin{array}{c}\text { EGFR/ALK } \\
\text { WT }\end{array}$ & & $37 \%$ & $18.00 \%$ & 8.3 & 6.8 & \multicolumn{2}{|c|}{$\begin{array}{c}0.62(0.52- \\
0.74)\end{array}$} & $67.30 \%$ & $60.60 \%$ & 19.2 & 14.7 & \multicolumn{2}{|c|}{$\begin{array}{c}0.78(0.64- \\
0.96)\end{array}$} & $63.50 \%$ & $48.00 \%$ & \\
\hline $\begin{array}{c}\text { EGFR/ALK } \\
M T\end{array}$ & & $37 \%$ & $21.00 \%$ & 9.7 & 6.1 & \multicolumn{2}{|c|}{$\begin{array}{c}0.59(0.37- \\
0.94)\end{array}$} & & & & & & & & & \\
\hline $\begin{array}{c}\text { PD-L1 high, } \\
\text { WT }\end{array}$ & & $53 \%$ & $14.10 \%$ & 12.6 & 6.8 & \multicolumn{2}{|c|}{$\begin{array}{c}0.39(0.25- \\
0.60)\end{array}$} & & & & & & & & & \\
\hline $\begin{array}{c}\text { PD-L1 low/ } \\
\text { negative, } \\
\text { WT }\end{array}$ & & $32 \%$ & $18.90 \%$ & 8 & 6.8 & \multicolumn{2}{|c|}{$\begin{array}{c}0.68(0.56- \\
0.82)\end{array}$} & & & & & & & & & \\
\hline $\begin{array}{l}\text { PD-L1 nega- } \\
\text { tive, WT }\end{array}$ & & $29 \%$ & $18.30 \%$ & 7.1 & 6.9 & \multicolumn{2}{|c|}{$\begin{array}{c}0.77(0.61- \\
0.99)\end{array}$} & & & & & & & & & \\
\hline $\begin{array}{c}\text { Key- } \\
\text { Note-021 } \\
\text { (19) }\end{array}$ & \multicolumn{2}{|c|}{10.6} & & & & & & & & & & & & & & \\
\hline Overall & & & $77 \%$ & $63 \%$ & 13 & 8.9 & & $\begin{array}{l}53(0.31- \\
0.91)\end{array}$ & $92 \%$ & $92 \%$ & & & & $\begin{array}{l}90(0.42- \\
1.91)\end{array}$ & $55 \%$ & $29 \%$ \\
\hline PD-L1 21\% & & & & & & & & & & & & & & & $54 \%$ & $38 \%$ \\
\hline PD-L1 $1 \geq 50 \%$ & & & & & & & & & & & & & & & $80 \%$ & $35 \%$ \\
\hline $\begin{array}{l}\text { Key- } \\
\text { Note-189 } \\
(20)\end{array}$ & 10.5 & & & & & & & & & & & & & & & \\
\hline Overall & & & $4 \%$ & $17.30 \%$ & 8.8 & 4.9 & & $\begin{array}{l}52(0.43- \\
0.64)\end{array}$ & $69.20 \%$ & $49.40 \%$ & UR & 11.3 & & $\begin{array}{l}49(0.38- \\
0.64)\end{array}$ & $47.60 \%$ & $18.90 \%$ \\
\hline PD-L1 <1\% & & & & & & & & $\begin{array}{l}75(0.53- \\
1.05)\end{array}$ & $61.70 \%$ & $52.20 \%$ & & & & $\begin{array}{l}59(0.38- \\
0.92)\end{array}$ & $32.30 \%$ & $14.30 \%$ \\
\hline PD-L1 $11 \%$ & & & & & & & & $\begin{array}{l}44(0.34- \\
0.57)\end{array}$ & & & & & & $\begin{array}{l}47(0.34- \\
0.66)\end{array}$ & & \\
\hline PD-L1 $\geq 50 \%$ & & & & & & & & $\begin{array}{l}36(0.25- \\
0.52)\end{array}$ & $73.00 \%$ & $48.10 \%$ & & & & $\begin{array}{l}42(0.26- \\
0.68)\end{array}$ & $61.40 \%$ & $22.90 \%$ \\
\hline $\begin{array}{c}\text { Key- } \\
\text { Note-407 } \\
(21)\end{array}$ & 7.8 & & & & & & & & & & & & & & & \\
\hline Overall & & & & & 6.4 & 4.8 & & $\begin{array}{l}56(0.45- \\
0.70)\end{array}$ & $65.20 \%$ & $48.30 \%$ & 15.9 & 11.3 & & $\begin{array}{l}64(0.49- \\
0.85)\end{array}$ & $60.30 \%$ & $32.90 \%$ \\
\hline PD-L1 <1\% & & & & & & & & $\begin{array}{l}58(0.47- \\
0.98)\end{array}$ & & & & & & $\begin{array}{l}61(0.38- \\
0.98)\end{array}$ & & \\
\hline PD-L1 $11 \%$ & & & & & & & & & & & & & & $\begin{array}{l}65(0.45- \\
0.92)\end{array}$ & & \\
\hline PD-L1 $\geq 50 \%$ & & & & & & & & $\begin{array}{l}37(0.24- \\
0.58)\end{array}$ & & & & & & $\begin{array}{l}64(0.37- \\
1.10)\end{array}$ & & \\
\hline $\begin{array}{c}\text { Key- } \\
\text { Note-024 } \\
(24)\end{array}$ & 25.2 & & & & & & & & & & & & & & & \\
\hline Overall & & & $.10 \%$ & $50.30 \%$ & 10.3 & 6.7 & & $\begin{array}{l}50(0.37- \\
0.68)\end{array}$ & $70.30 \%$ & $54.80 \%$ & 30 & 14.2 & & $\begin{array}{l}63(0.47- \\
0.86)\end{array}$ & $44.80 \%$ & $27.80 \%$ \\
\hline
\end{tabular}


Citation: Ibrahim EM, Refae AA, Bayer AM, Al-Masri OA, Eldahna WM, et al. Checkpoint Inhibitors in the First-Line Setting in Advanced Non-Small Cell Lung Cancer: A Meta-AnalysisJ Cancer Sci. 2019;6(1): 14.

ISSN: $2377-9292$

\begin{tabular}{|c|c|c|c|c|c|c|c|c|c|c|c|c|c|}
\hline $\begin{array}{l}\text { MYSTIC } \\
(22)\end{array}$ & $N R$ & & & & & & & & & & & & \\
\hline $\begin{array}{l}\text { Durvalum- } \\
\text { ab vs. CTX }\end{array}$ & & $32.30 \%$ & $14.30 \%$ & 4.7 & 5.4 & & & & & & & & \\
\hline PD-L1 <1\% & & & & & & & $46 \%$ & $48 \%$ & 10.1 & 10.3 & $\begin{array}{c}1.18(0.86- \\
1.62)\end{array}$ & & \\
\hline PD-L1 1 1\% & & & & & & & $60 \%$ & $61 \%$ & 14.6 & 12.3 & $\begin{array}{c}0.88(0.73- \\
1.07)\end{array}$ & & \\
\hline PD-L1 $\geq 50 \%$ & & & & & & & $70 \%$ & $58 \%$ & 18.3 & 12.7 & $\begin{array}{c}0.76(0.55- \\
1.04)\end{array}$ & & \\
\hline Low TMB & & & & & & & $52 \%$ & $50 \%$ & 12.2 & 11.6 & $\begin{array}{c}0.92(0.72- \\
1.17)\end{array}$ & & \\
\hline High TMB & & & & & & & $54 \%$ & $40 \%$ & 11 & 10.5 & $\begin{array}{c}0.80(0.59- \\
1.08)\end{array}$ & & \\
\hline $\begin{array}{l}\text { Durvalum- } \\
\text { ab + Treme- } \\
\text { limumab } \\
\text { vs. CTX }\end{array}$ & & $25.80 \%$ & $14.30 \%$ & 3.9 & 5.4 & & & & & & & & \\
\hline PD-L1 < $1 \%$ & & & & & & & $50 \%$ & $49 \%$ & 11.9 & 10.3 & $\begin{array}{c}0.73(0.51- \\
1.04)\end{array}$ & & \\
\hline PD-L1 $11 \%$ & & & & & & & $48 \%$ & $50 \%$ & 10.9 & 12.3 & $\begin{array}{c}1.01(0.83- \\
1.21)\end{array}$ & & \\
\hline PD-L1 $\geq 25 \%$ & & $54.90 \%$ & $18.00 \%$ & & & $\begin{array}{c}1.05(0.72- \\
1.53)\end{array}$ & $58 \%$ & $59 \%$ & 11.9 & 12.9 & $\begin{array}{c}0.85(0.61- \\
1.17)\end{array}$ & $34.40 \%$ & $37.70 \%$ \\
\hline PD-L1 $\geq 50 \%$ & & & & & & & $58 \%$ & $59 \%$ & 15.2 & 12.7 & $\begin{array}{c}0.77(0.56- \\
1.07)\end{array}$ & & \\
\hline Low TMB & & & & & & & $57 \%$ & $50 \%$ & 8.5 & 11.6 & $\begin{array}{c}1.23(0.94- \\
1.58)\end{array}$ & & \\
\hline High TMB & & & & & & & $50 \%$ & $40 \%$ & 16.5 & 10.5 & $\begin{array}{c}0.62(0.45- \\
0.86)\end{array}$ & & \\
\hline $\begin{array}{c}\text { Key- } \\
\text { Note-042 } \\
\text { (28) }\end{array}$ & 12.8 & & & & & & & & & & & & \\
\hline & & & & & & & \multicolumn{2}{|c|}{ 2-Yros } & & & & & \\
\hline PD-L1 $\geq 1 \%$ & & & & 5.4 & 6.5 & $\begin{array}{c}1.07(0.94- \\
1.21)\end{array}$ & $39 \%$ & $28 \%$ & 16.7 & 12.1 & $\begin{array}{c}0.81(0.71- \\
0.93)\end{array}$ & $27 \%$ & $27 \%$ \\
\hline PD-L1 $\geq 20 \%$ & & & & 6.2 & 6.6 & $\begin{array}{c}0.94(0.80- \\
1.11)\end{array}$ & $41 \%$ & $30 \%$ & 17.7 & 13 & $\begin{array}{c}0.77(0.64- \\
0.92)\end{array}$ & $33 \%$ & $29 \%$ \\
\hline PD-L1 $\geq 50 \%$ & & & & 7.1 & 6.4 & $\begin{array}{c}0.81(0.67- \\
0.99)\end{array}$ & $45 \%$ & $30 \%$ & 20 & 12.2 & $\begin{array}{c}0.69(0.56- \\
0.85)\end{array}$ & $39 \%$ & $32 \%$ \\
\hline
\end{tabular}

CTR: Control Arm; CR: Confidence Interval; Exp: Experimental Arm; HR: Hazard Ratio; m: months; NR: Not Reported; ORR: Objective Response Rate; PFS: Progression-Free Survival; OS: Overall Survival; PD-L1: Programmed Death Legend-1; TMB: Tumor Mutational Burden; WT: Wild Type; Yr: Year

where CPIs were used as monotherapy versus CTX. The pooled effect estimated a $\mathrm{HR}=0.79$ (95\% CI, 0.71-0.87); $\mathrm{P}=<0.0001)$, indicating a $21 \%$ reduction in the risk of death, favoring CPIs. The model showed no heterogeneity $\left(I^{2}=28 \%\right)$.

Figure 5 shows the analyses of the pooled effect on OS of CPIs versus CTX in relevant subgroups as derived from three studies (16, $24,28)$. CPIs was associated with favorable OS regardless of age, gender, ECOG status, histology, and PD-L1 expression $\geq 50 \%$.

\section{Analysis of ORR}

Figure 6 shows that the ORR attained with CPIs was not significantly different from that achieved using CTX $(\mathrm{OR}=1.20$; 95\% CI, 0.94-1.53; P = 0.15), with a demonstrated heterogeneity $\left(I^{2}\right.$ $=70 \%)$. The pooled OR didn't significantly changed by repeating the analysis with the inclusion of only patients with PD-L1 score of $\geq 50 \%$ from KeyNote-42 study.

\section{Publication bias}

In the analysis of the PFS there was no asymmetry in the shape of the funnel plot. The fail-safe $\mathrm{N}$ method showed that 38 studies are required to accept the null hypothesis. The trim and fill method suggested that there were 2 studies needed to be imputed to make the funnel plot symmetric. For the OS analysis, the funnel plot seemed symmetric and the required studies were 75 and 0 for the two methods, respectively.

\section{CPIs plus CTX versus CTX only}

\section{Analysis of PFS}

Figure 7 shows that combining CPIs plus CTX resulted into 39\% reduction in the risk of progression as compared with using CTX alone $(\mathrm{HR}=0.61 ; 95 \% \mathrm{CI} 0.57-0.66 ; \mathrm{P}<0.0001)$. Meta-regression was not required as there was no demonstrated heterogeneity $\left(I^{2}=10 \%\right)$. 


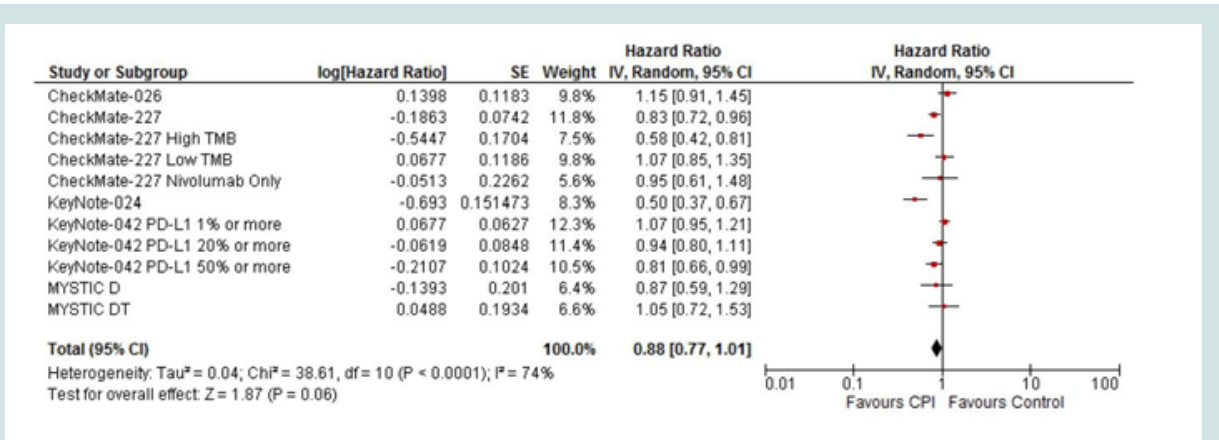

Figure 2: Forest plot of the hazard ratio (HR) for progression-free survival for studies where a checkpoint inhibitor (CPI) was compared with chemotherapy. Squares represent the HR of each single study (size of the square reflects the study-specific statistical weight); horizontal lines represent $95 \%$ confidence intervals (Cls); diamonds represent the pooled estimates, based on a random-effects model. All statistical tests were two-sided. Abbreviations: MYSTIC D, durvalumab; MYSTIC DT, duravalumab plus tremelimumab; TMB, tumor mutation burden.

\begin{tabular}{|c|c|c|c|c|}
\hline End point & Data set & Covariates & Incremental $\mathbf{R}^{2}$ & $P$ value \\
\hline \multirow{3}{*}{ PFS } & \multirow{3}{*}{ CIPs monotherapy versus CTX } & Intercept & $0 \%$ & \\
\hline & & Number of patients in experimental arms & $61 \%$ & 0.012 \\
\hline & & Proportion of male gender in experimental arms & $81 \%$ & 0.002 \\
\hline \multirow{3}{*}{ os } & \multirow{3}{*}{ CIPs plus CTX versus CTX } & Intercept & 0 & \\
\hline & & PD-L1 expression: high vs. negative & $77 \%$ & 0.04 \\
\hline & & PD-L1 expression: positive vs. negative & $63 \%$ & 0.1 \\
\hline
\end{tabular}

Figure 8 shows the analyses of the pooled effect on PFS of CPIs plus CTX versus CTX alone in patient subgroups. CPIs plus CTX attained a significant PFS in all examined subgroups, noteworthy, a $60 \%$ decrease in the risk of progression or death among patients with PD-L1 expression of $\geq 50 \%$ (HR $=0.40 ; 95 \%$ CI, 0.34-0.48).

\section{Analysis of OS}

Figure 9 shows that as compared with CTX alone, CPIs plus CTX decreased mortality by $26 \%(\mathrm{HR}=0.74 ; 95 \% \mathrm{CI}, 0.63-0.88 ; \mathrm{P}<0.0001)$. There was moderate heterogeneity $\left(I^{2}=65 \%\right)$. The meta-regression analysis identified PD-L1 expression and median follow-up duration as the variables that could explain $100 \%$ of OS heterogeneity (Table 3). There was a positive association between longer follow-up and effects size, i. e. lower benefit.

Figure 10 shows the analyses of the pooled effect on OS of CPIs plus CTX versus CTX alone in patient subgroups. The analyses favored the combination of CPIs plus CTX over CTX only in all subgroups with no demonstrated heterogeneity. For the patients whose tumor expressed PD-L1 $\geq 50 \%$, a $35 \%$ reduction in mortality was demonstrated ( $\mathrm{HR}=0.65 ; 95 \% \mathrm{CI}, 0.52-0.81)$.

\section{Analysis of ORR}

Figure 11 shows that the combination regimens doubled the ORR as compared with CTX alone (OR $=2.20$; 95\% CI, 1.71-2.82; $\mathrm{P}<0.0001)$. However, there was moderate heterogeneity $\left(I^{2}=56 \%\right)$.

\section{Publication bias}

For the PFS analysis, the funnel plot was symmetric. The fail-safe $\mathrm{N}$ method showed that 2171 studies are required to accept the null hypothesis. The trim and fill method suggested that there is 0 study needed to be imputed to make the funnel plot symmetric. For the OS analysis, the required studies were 167 and 0 for the two methods, respectively.

\section{Discussion}

The current meta-analysis showed that when used as monotherapy in previously untreated patients, CPIs attained a similar PFS benefit compared to CTX including comparisons across patient subgroups except for patients with high TMB as reported from two studies using nivolumab monotherapy or nivolumab plus ipilimumab [16,27]. The predicted improved outcome of high TMB was first demonstrated in associated with pembrolizumab in a subset of patients in the KEYNOTE-001 trial [29]. TMB may be used as an independent biomarker to define patients who would attain the highest advantage from immunotherapy as the benefit associated with high TMB was shown to be independent of PD-L1 expression [16,27].

Conversely, combining CPIs and CTX versus CTX alone showed favorable improvement in PFS with an overall 39\% reduction in the risk of disease progression, with benefit attained in all subgroups. Moreover, analysis of the effects size on OS, showed $21 \%$ and $26 \%$ reduction in the risk of death, in the first and second cohorts, respectively. The favorable effect was attained across all relevant subgroups. While no significant difference in ORR was seen between CPIs versus CTX, combining CPIs plus CTX produced a significant improvement in disease response as compared with CTX alone.

Of all analyzed subgroups, patients expressing high PD-L1 of $\geq 50 \%$ attained the most consistent benefit in all comparisons. Several trials have shown a close association between the magnitude of benefit and the level of PD-L1 expression in first-line (Table 2), 
Citation: Ibrahim EM, Refae AA, Bayer AM, Al-Masri OA, Eldahna WM, et al. Checkpoint Inhibitors in the First-Line Setting in Advanced Non-Small Cell Lung Cancer: A Meta-AnalysisJ Cancer Sci. 2019;6(1): 14

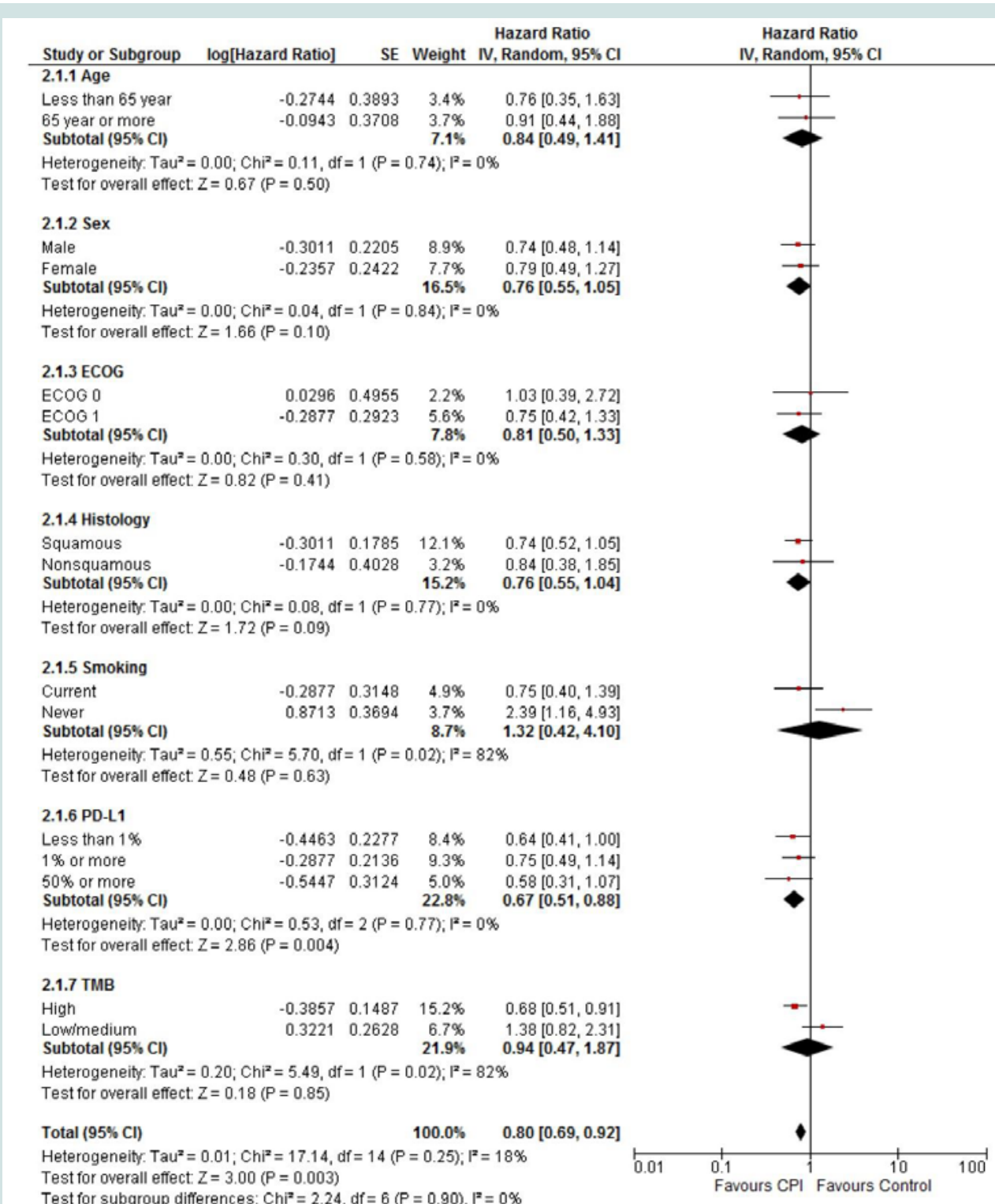

Figure 3: Forest plot of the hazard ratio (HR) for progression-free survival for patient subgroups for studies where a checkpoint inhibitor (CPI) was compared with chemotherapy. Squares represent the HR of each single study (size of the square reflects the study-specific statistical weight); horizontal lines represent $95 \%$ confidence intervals (Cls); diamonds represent the pooled estimates, based on a random-effects model. All statistical tests were two-sided.

\begin{tabular}{|c|c|c|c|c|c|c|c|c|}
\hline Study or Subgroup & log[Hazard Ratio] & SE & Weight & $\begin{array}{c}\text { Hazard Ratio } \\
\mathrm{IV} \text {, Random, } 95 \% \mathrm{Cl}\end{array}$ & \multicolumn{4}{|c|}{\begin{tabular}{c}
\multicolumn{1}{c}{ Hazard Ratio } \\
IV, Random, $95 \% \mathrm{CI}$
\end{tabular}} \\
\hline CheckMate-026 & 0.0198 & 0.1238 & $12.7 \%$ & $1.02[0.80,1.30]$ & \multicolumn{4}{|c|}{$t$} \\
\hline KeyNote-024 & -0.462 & 0.1588 & $8.5 \%$ & $0.63[0.46,0.86]$ & \multicolumn{4}{|c|}{$\rightarrow$} \\
\hline KeyNote-042 PD-L1 $1 \%$ or more & -0.2107 & 0.0705 & $25.9 \%$ & $0.81[0.71,0.93]$ & \multirow{2}{*}{\multicolumn{4}{|c|}{-}} \\
\hline KeyNote-042 PD-L1 $20 \%$ or more & -0.2614 & 0.0908 & $19.5 \%$ & $0.77[0.64,0.92]$ & \multirow{2}{*}{\multicolumn{4}{|c|}{$\div$}} \\
\hline KeyNote- 042 PD-L1 $50 \%$ or more & -0.3711 & 0.1064 & $15.8 \%$ & $0.69[0.56,0.85]$ & & & & \\
\hline MYSTIC D & -0.2744 & 0.1496 & $9.4 \%$ & $0.76[0.57,1.02]$ & \multicolumn{4}{|c|}{$\rightarrow$} \\
\hline MYSTIC DT & -0.1625 & 0.1643 & $8.1 \%$ & $0.85[0.62,1.17]$ & \multicolumn{4}{|c|}{$\rightarrow$} \\
\hline Total $(95 \% \mathrm{Cl})$ & & & $100.0 \%$ & $0.79[0.71,0.87]$ & \multicolumn{4}{|c|}{1} \\
\hline \multicolumn{4}{|c|}{$\begin{array}{l}\text { Heterogeneity: Tau }=0.00 ; \mathrm{Ch}^{2}=8.38, \mathrm{df}=6(\mathrm{P}=0.21) ; \mathrm{P}^{2}=28 \% \\
\text { Test for overall effect } Z=4.73(\mathrm{P}<0.00001)\end{array}$} & & 0.01 & $\begin{array}{l}1 \\
0.1 \\
\text { Favours CPI }\end{array}$ & $\begin{array}{c}10 \\
10 \\
\text { Favours Control }\end{array}$ & $\overrightarrow{100}$ \\
\hline
\end{tabular}

Figure 4: Forest plot of the hazard ratio (HR) for overall survival for studies where a checkpoint inhibitors (CPI) was compared with chemotherapy. Squares represent the HR of each single study (size of the square reflects the study-specific statistical weight); horizontal lines represent $95 \%$ confidence intervals (Cls); diamonds represent the pooled estimates, based on a random-effects model. All statistical tests were two-sided. Abbreviations: MYSTIC D, durvalumab; MYSTIC DT, duravalumab plus tremelimumab. 
Citation: Ibrahim EM, Refae AA, Bayer AM, Al-Masri OA, Eldahna WM, et al. Checkpoint Inhibitors in the First-Line Setting in Advanced Non-Small Cell Lung Cancer: A Meta-AnalysisJ Cancer Sci. 2019;6(1): 14

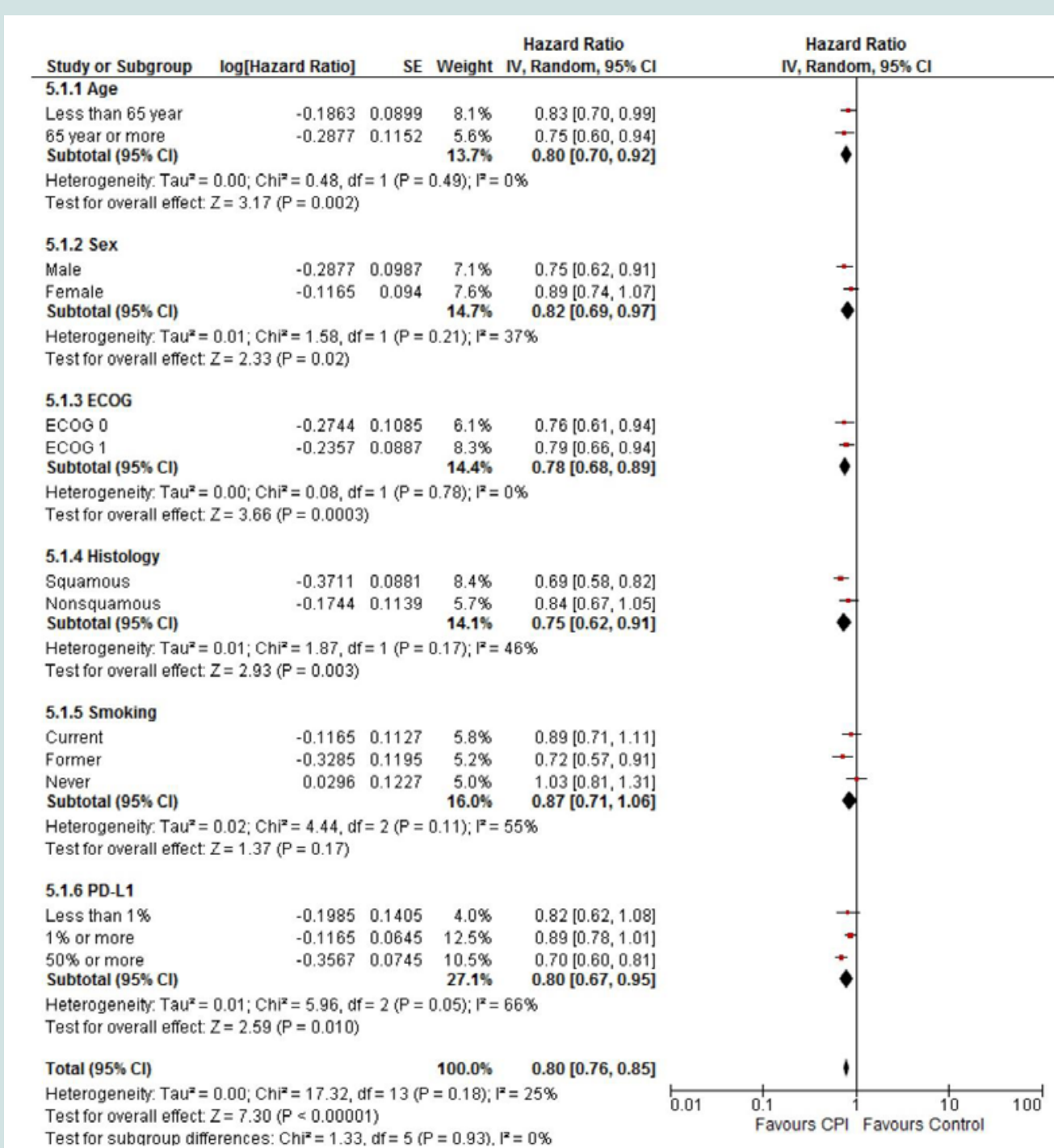

Figure 5: Forest plot of the hazard ratio (HR) for overall survival for patient subgroups for studies where a checkpoint inhibitors (CPI) was compared with chemotherapy. Squares represent the HR of each single study (size of the square reflects the study-specific statistical weight); horizontal lines represent $95 \%$ confidence intervals (Cls); diamonds represent the pooled estimates, based on a random-effects model. All statistical tests were two-sided.

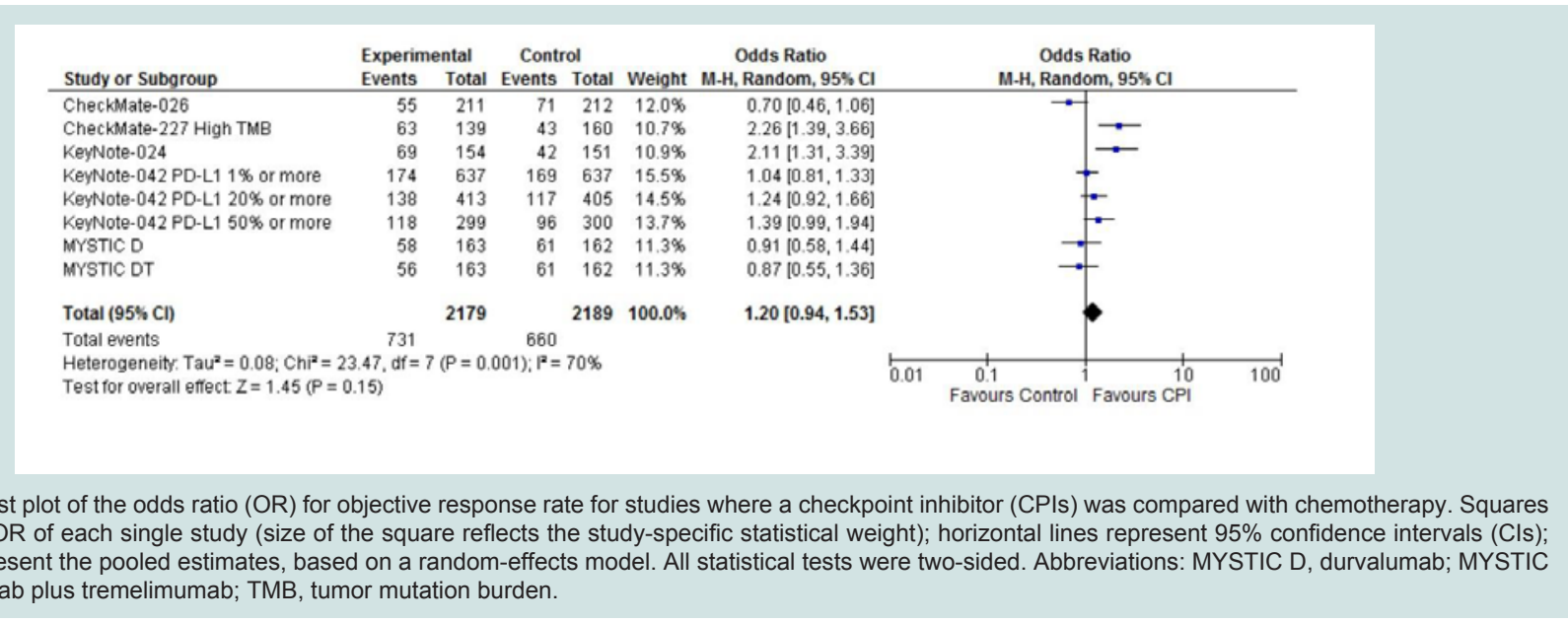


Citation: Ibrahim EM, Refae AA, Bayer AM, Al-Masri OA, Eldahna WM, et al. Checkpoint Inhibitors in the First-Line Setting in Advanced Non-Small Cell Lung Cancer: A Meta-AnalysisJ Cancer Sci. 2019;6(1): 14

\begin{tabular}{|c|c|c|c|c|c|c|c|c|}
\hline \multirow{2}{*}{$\begin{array}{l}\text { Study or Subgroup } \\
\text { IMpower-130 }\end{array}$} & \multirow{2}{*}{$\begin{array}{r}\text { log[Hazard Ratio] } \\
-0.4463\end{array}$} & & Weight & $\begin{array}{l}\text { Hazard Ratio } \\
\text { IV, Random, } 95 \% \mathrm{Cl}\end{array}$ & \multicolumn{3}{|c|}{$\begin{array}{c}\text { Hazard Ratio } \\
\text { IV. Random, } 95 \% \mathrm{Cl}\end{array}$} & \\
\hline & & & $12.0 \%$ & $0.64[0.53,0.77]$ & & -1 & & \\
\hline IMpower-131 Nab & -0.3425 & 0.0918 & $12.6 \%$ & $0.71[0.59,0.85]$ & & $*$ & & \\
\hline IMpower-132 & -0.5108 & 0.093 & $12.3 \%$ & $0.60[0.50,0.72]$ & & $=$ & & \\
\hline IMpower-150 All & -0.4943 & 0.0846 & $14.5 \%$ & $0.61[0.52,0.72]$ & & $=$ & & \\
\hline IMpower-150 Mut & -0.5276 & 0.2376 & $2.1 \%$ & $0.59[0.37,0.94]$ & & & & \\
\hline IMpower-150 Teff-High WT & -0.6733 & 0.1468 & $5.4 \%$ & $0.51[0.38,0.68]$ & & $\rightarrow$ & & \\
\hline IMpower-150 Teff-Low WT & -0.2744 & 0.1176 & $8.1 \%$ & $0.76[0.60,0.96]$ & & $\rightarrow$ & & \\
\hline IMpower-150 WT & -0.478 & 0.0903 & $13.0 \%$ & $0.62[0.52,0.74]$ & & - & & \\
\hline KeyNote-021 & -0.6349 & 0.2758 & $1.6 \%$ & $0.53[0.31,0.91]$ & & & & \\
\hline KeyNote-189 & -0.6539 & 0.1059 & $9.8 \%$ & $0.52[0.42,0.64]$ & & - & & \\
\hline KeyNote-407 & -0.5798 & 0.1139 & $8.6 \%$ & $0.56[0.45,0.70]$ & & $\rightarrow$ & & \\
\hline \multicolumn{3}{|c|}{ Total $(95 \% \mathrm{Cl})$} & $100.0 \%$ & $0.61[0.57,0.66]$ & & 1 & & \\
\hline \multicolumn{4}{|c|}{$\begin{array}{l}\text { Heterogeneity: Tau }{ }^{2}=0.00 ; \mathrm{Ch}^{2}=11.09 \text {, df }=10(P=0.35) ; i^{2}=10 \% \\
\text { Test for overall effect } Z=13.89(P<0.00001)\end{array}$} & & 0.01 & ${ }^{0.1}{ }^{1}{ }^{1}$ & $\begin{array}{cc}10 \\
\text { Favours Control }\end{array}$ & $\overrightarrow{100}$ \\
\hline
\end{tabular}
chemotherapy alone. Squares represent the HR of each single study (size of the square reflects the study-specific statistical weight); horizontal lines represent 95\% confidence intervals (Cls); diamonds represent the pooled estimates, based on a random-effects model. All statistical tests were two-sided. Abbreviations: mut, mutated; Nab; nab-paclitaxel; WT, wild-type.

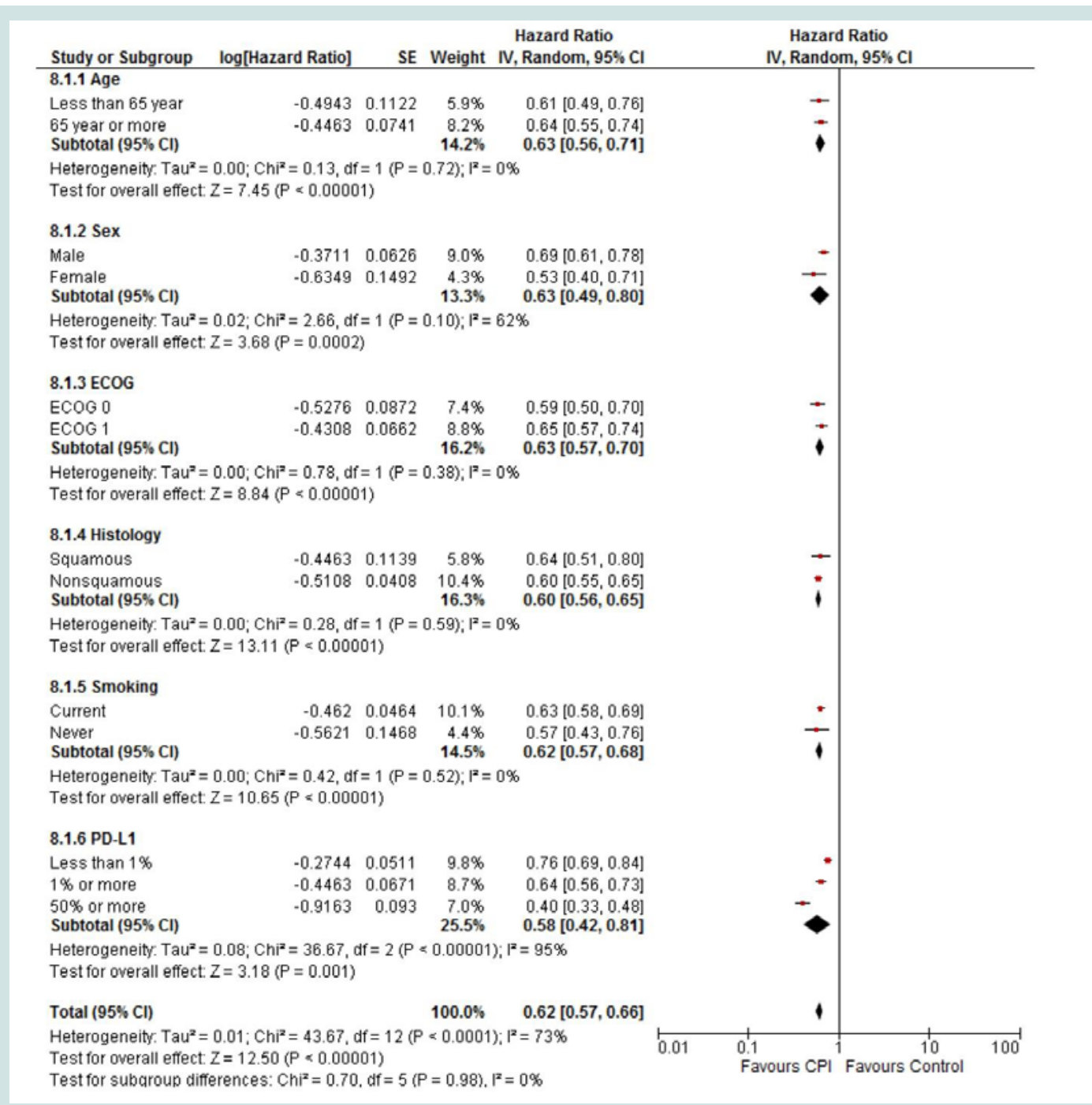

Figure 8: Forest plot of the hazard ratio (HR) for progression-free survival for patient subgroups for studies where a checkpoint inhibitor (CPI) plus chemotherapy was compared with chemotherapy alone. Squares represent the HR of each single study (size of the square reflects the study-specific statistical weight); horizontal lines represent $95 \%$ confidence intervals $(\mathrm{Cls})$; diamonds represent the pooled estimates, based on a random-effects model. All statistical tests were two-sided. 
Citation: Ibrahim EM, Refae AA, Bayer AM, Al-Masri OA, Eldahna WM, et al. Checkpoint Inhibitors in the First-Line Setting in Advanced Non-Small Cell Lung Cancer: A Meta-AnalysisJ Cancer Sci. 2019;6(1): 14

\begin{tabular}{|c|c|c|c|c|c|c|c|}
\hline Study or Subgroup & $\log [$ Hazard Ratio] & SE & Weight & $\begin{array}{l}\text { Hazard Ratio } \\
\text { IV, Random, } 95 \% \mathrm{Cl}\end{array}$ & $\begin{array}{r}\text { Hazard } \\
\text { IV, Randon }\end{array}$ & $\begin{array}{l}\text { Ratio } \\
\mathrm{m}, 95 \% \mathrm{Cl}\end{array}$ & \\
\hline IMpower-130 & -0.2357 & 0.11 & $16.9 \%$ & $0.79[0.64,0.98]$ & $\rightarrow$ & & \\
\hline IMpower-131 Nab & -0.0408 & 0.1053 & $17.3 \%$ & $0.96[0.78,1.18]$ & + & & \\
\hline IMpower-132 & -0.2107 & 0.1226 & $15.8 \%$ & $0.81[0.64,1.03]$ & $\rightarrow$ & & \\
\hline IMpower-150 WT & -0.2485 & 0.1059 & $17.2 \%$ & $0.78[0.63,0.96]$ & - & & \\
\hline KeyNote-021 & -0.1054 & 0.3839 & $4.1 \%$ & $0.90[0.42,1.91]$ & $\rightarrow$ & & \\
\hline KeyNote-189 & -0.7133 & 0.1363 & $14.7 \%$ & $0.49[0.38,0.64]$ & $=$ & & \\
\hline KeyNote- 407 & -0.4463 & 0.1448 & $14.0 \%$ & $0.64[0.48,0.85]$ & $\rightarrow$ & & \\
\hline Total $(95 \% \mathrm{Cl})$ & & & $100.0 \%$ & $0.74[0.63,0.88]$ & $\bullet$ & & \\
\hline \multicolumn{5}{|c|}{$\begin{array}{l}\text { Heterogeneity. Tau }=0.03 ; \mathrm{Chi}^{2}=17.35, \mathrm{df}=6(P=0.008) ;\left.\right|^{2}=65 \% \\
\text { Test for overall effect: } Z=3.44(P=0.0006)\end{array}$} & $\begin{array}{ll}0.01 & 0.1 \\
\text { Favours [experimental] } & 1 \\
\end{array}$ & $\begin{array}{c}10 \\
\text { Favours [control] }\end{array}$ & 100 \\
\hline
\end{tabular}

Figure 9: Forest plot of the hazard ratio (HR) for overall survival for studies where a checkpoint inhibitors (CPI) where a checkpoint inhibitor (CPI) plus chemotherapy was compared with chemotherapy alone. Squares represent the HR of each single study (size of the square reflects the study-specific statistical weight); horizontal lines represent $95 \%$ confidence intervals (Cls); diamonds represent the pooled estimates, based on a random-effects model. All statistical tests were two-sided. Abbreviations: Nab; nab-paclitaxel; WT, wild-type.

\begin{tabular}{|c|c|c|c|c|c|c|c|c|}
\hline \multirow{2}{*}{$\frac{\text { Study or Subgroup }}{\text { 10.1.1 Age }}$} & log[Hazard Ratio] & SE & Weight & $\begin{array}{l}\text { Hazard Ratio } \\
\text { IV, Random, } 95 \% \mathrm{Cl}\end{array}$ & \multicolumn{4}{|c|}{$\begin{array}{c}\text { Hazard Ratio } \\
\mathrm{IV} \text {, Random, } 95 \% \mathrm{Cl}\end{array}$} \\
\hline & & & & & & & & \\
\hline Less than 65 year & -0.4463 & 0.1739 & $4.0 \%$ & $0.64[0.46,0.90]$ & & $\rightarrow$ & & \\
\hline 65 year or more & -0.3147 & 0.0836 & $17.4 \%$ & $0.73[0.62,0.86]$ & & $=$ & & \\
\hline Subtotal $(95 \% \mathrm{Cl})$ & & & $21.5 \%$ & $0.71[0.61,0.83]$ & & $\bullet$ & & \\
\hline \multicolumn{9}{|c|}{$\begin{array}{l}\text { Heterogeneity: } \text { Tau }^{z}=0.00 ; \mathrm{Chi}^{2}=0.47, \mathrm{df}=1(\mathrm{P}=0.50) ; \mathrm{I}^{2}=0 \% \\
\text { Test for overall effect: } Z=4.50(P<0.00001)\end{array}$} \\
\hline \multicolumn{9}{|l|}{ 10.1.2 Sex } \\
\hline Male & -0.2744 & 0.0919 & $14.4 \%$ & $0.76[0.63,0.91]$ & & - & & \\
\hline Female & -0.821 & 0.2789 & $1.6 \%$ & $0.44[0.25,0.76]$ & & & & \\
\hline Subtotal $(95 \%$ Cl) & & & $16.0 \%$ & $0.62[0.37,1.04]$ & & $<$ & & \\
\hline \multirow{2}{*}{\multicolumn{9}{|c|}{$\begin{array}{l}\text { Heterogeneity: } \text { Tau }^{2}=0.11 ; C \mathrm{Ch}^{2}=3.46, \mathrm{df}=1(P=0.06) ; \mathrm{F}^{2}=71 \% \\
\text { Test for overall effect: } Z=1.82(P=0.07)\end{array}$}} \\
\hline & & & & & & & & \\
\hline \multicolumn{9}{|l|}{ 10.1.3 ECOG } \\
\hline ECOG 0 & -0.4943 & 0.2152 & $2.6 \%$ & $0.61[0.40,0.93]$ & & - & & \\
\hline ECOG 1 & -0.4155 & 0.1045 & $11.2 \%$ & $0.66[0.54,0.81]$ & & $=$ & & \\
\hline Subtotal $(95 \% \mathrm{Cl})$ & & & $13.8 \%$ & $0.65[0.54,0.78]$ & & $\bullet$ & & \\
\hline \multirow{2}{*}{\multicolumn{9}{|c|}{$\begin{array}{l}\text { Heterogeneity: Tau }=0.00 ; \mathrm{Chi}^{2}=0.11, \mathrm{df}=1(\mathrm{P}=0.74) ; \mathrm{I}^{2}=0 \% \\
\text { Test for overall effect: } Z=4.58(P<0.00001)\end{array}$}} \\
\hline & & & & & & & & \\
\hline \multicolumn{9}{|l|}{ 10.1.4 Histology } \\
\hline Squamous & -0.2357 & 0.2047 & $2.9 \%$ & $0.79[0.53,1.18]$ & & $一$ & & \\
\hline Nonsquamous & -0.3285 & 0.1024 & $11.6 \%$ & $0.72[0.59,0.88]$ & & $\mp$ & & \\
\hline Subtotal $(95 \% \mathrm{Cl})$ & & & $14.5 \%$ & $0.73[0.61,0.88]$ & & $\bullet$ & & \\
\hline \multirow{2}{*}{\multicolumn{9}{|c|}{$\begin{array}{l}\text { Heterogeneity. Tau }{ }^{2}=0.00 ; \mathrm{Chi}^{2}=0.16, \mathrm{df}=1(P=0.69) ; \mathrm{I}^{2}=0 \% \\
\text { Test for overall effect. } Z=3.38(P=0.0007)\end{array}$}} \\
\hline & & & & & & & & \\
\hline \multicolumn{9}{|l|}{ 10.1.5 Smoking } \\
\hline Current & -0.3285 & 0.1306 & $7.1 \%$ & $0.72[0.56,0.93]$ & & $\rightarrow$ & & \\
\hline Never & -0.7985 & 0.3123 & $1.2 \%$ & $0.45[0.24,0.83]$ & & & & \\
\hline Subtotal $(95 \% \mathrm{Cl})$ & & & $8.4 \%$ & $0.62[0.40,0.95]$ & & $>$ & & \\
\hline \multirow{2}{*}{\multicolumn{9}{|c|}{$\begin{array}{l}\text { Heterogeneity. Tau }=0.05 ; \mathrm{Chi}^{2}=1.93, \mathrm{df}=1(\mathrm{P}=0.17) ; \mathrm{P}^{2}=48 \% \\
\text { Test for overall effect. } Z=2.18(P=0.03)\end{array}$}} \\
\hline & & & & & & & & \\
\hline \multicolumn{9}{|l|}{ 10.1.6 PD-L1 } \\
\hline Less than $1 \%$ & -0.2744 & 0.0863 & $16.4 \%$ & $0.76[0.64,0.90]$ & & $*$ & & \\
\hline $1 \%$ or more & -0.5978 & 0.165 & $4.5 \%$ & $0.55[0.40,0.76]$ & & $\rightarrow$ & & \\
\hline $50 \%$ or more & -0.5276 & 0.1554 & $5.0 \%$ & $0.59[0.44,0.80]$ & & $\overrightarrow{-}$ & & \\
\hline Subtotal $(95 \%$ Cl) & & & $25.9 \%$ & $0.65[0.52,0.81]$ & & $\bullet$ & & \\
\hline \multirow{2}{*}{\multicolumn{9}{|c|}{$\begin{array}{l}\text { Heterogeneity: } \operatorname{Tau}^{2}=0.02 ; \mathrm{Chi}^{2}=4.14, \mathrm{df}=2(P=0.13) ; \mathrm{I}^{2}=52 \% \\
\text { Test for overall effect: } Z=3.91(P \approx 0.0001)\end{array}$}} \\
\hline & & & & & & & & \\
\hline & & & & $0.70[0.65,0.75]$ & & 1 & & \\
\hline \multirow{2}{*}{\multicolumn{5}{|c|}{$\begin{array}{l}\text { Heterogeneity. } \text { Tau }^{2}=0.00 ; C h i^{2}=11.53, d f=12(P=0.48) ; I^{2}=0 \% \\
\text { Test for overall effect. } Z=10.35(P<0.00001) \\
\text { Test for subaroup differences: } C \mathrm{Ch}^{2}=1.72, \mathrm{df}=5(P=0.89) . \mathrm{I}^{2}=0 \%\end{array}$}} & 0.01 & Favours CPI & $\begin{array}{c}10 \\
\text { Favours Control } \\
1\end{array}$ & 100 \\
\hline & & & & & & & & \\
\hline
\end{tabular}

Figure 10: Forest plot of the hazard ratio (HR) for overall survival for patient subgroups for studies where a checkpoint inhibitor (CPI) plus chemotherapy was compared with chemotherapy alone. Squares represent the HR of each single study (size of the square reflects the study-specific statistical weight); horizontal lines represent $95 \%$ confidence intervals (Cls); diamonds represent the pooled estimates, based on a random-effects model. All statistical tests were two-sided. 


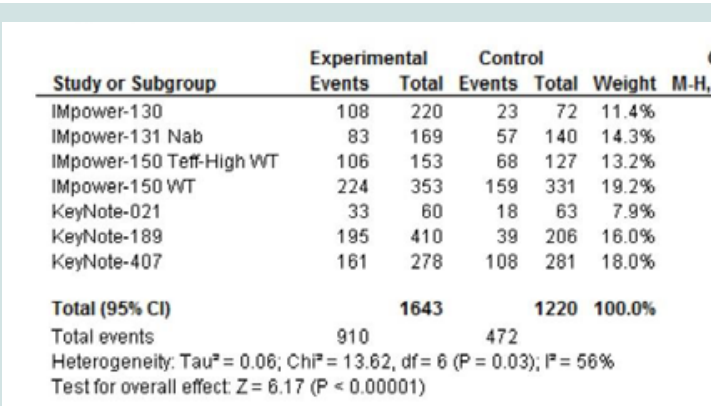

Odds Ratio

Random, $95 \% \mathrm{Cl}$

$2.05[1.17,3.60]$

$1.41[0.89,2.21]$

$1.96[1.20,3.19]$

$1.88[1.38,2.55]$

$3.06[1.45,6.45]$

$3.88[2.61,5.79]$

$2.20[1.57,3.09]$

$2.20[1.71,2.82]$

Test for overall effect $Z=6.17(P<0.00001)$

Figure 11: Forest plot of the Odds Ratio (OR) for objective response rate for studies where a checkpoint inhibitor (CPI) plus chemotherapy was compared with chemotherapy alone. Squares represent the OR of each single study (size of the square reflects the study-specific statistical weight); horizontal lines represent $95 \%$ confidence intervals (Cls); diamonds represent the pooled estimates, based on a random-effects model. All statistical tests were two-sided. Abbreviations: Nab, nab-paclitaxel; WT, wild-type.

or in subsequent lines settings (CHECKMATE-057, and OAK $[30,31]$. However, there have been evidence that survival benefit could be attained with atezolizumab plus CTX $[17,18,26]$, or with pembrolizumab with CTX in the first-line setting even for PD-L1 negative patients $[20,21]$. On the other hand, in the KEYNOTE-042 no OS advantage was achieved in those patients with $1 \%-49 \%$ PDL1 expression [28]. Such observations suggested that PD-L1 score alone is not a perfect predictor biomarker and its role needs to be reexamined. In a phase II trial of patients with colorectal cancer, while pembrolizumab benefited patients with Mismatch Repair (MMR)deficient, those with MMR-proficient gained no benefit [32]. Enough data about MMR in NSCLC are lacking.

The relationship between the effects of CPIs and smoking history was rather interesting. In the analysis of PFS, patients with current smoking history showed a trend of more benefit with CPIs as compared with never smokers. The same pattern was shown in the analysis of OS where current and former smokers benefited more compared with never smokers. The benefit gained by CPIs among ever smoker was consistent with results reported from other studies $[33,34]$.

Our current meta-analysis demonstrated several strengths. First, the analysis included all relevant randomized trials that tested CPIs in the first-line setting either as monotherapy or in combination with CTX and used the updated published data of 7,095 patients. Second, the analysis quantified the outcomes in several patient subgroups, most importantly the influence of age, gender, TMB, and PD-L1 expression. Third, we were able to show that the studies that examined CPIs in the first-setting showed insignificant publication biases.

Fourth, the meta-analysis analyzed the demonstrated heterogeneity in the pooled effects of PFS or OS, an exercise that was not attempted in the other published meta-analyses. The number of patients included in the experimental arms, male gender proportion, PD-L1 expression, and median duration of follow-up prevailed as the variables that explained most of the variance across studies. Patients number was positively associated with HR suggesting lesser benefit with increasing study population. It is certain that larger studies are more able to reliably reflect the true benefit of an intervention. The lower benefit, albeit remains significant, in association with larger studies. On the contrary, small studies can produce false-positive results, or they over-estimate the true effect [35]. Moreover, since the introduction of CPIs the survival of patients with metastatic NSCLC has significantly improved [36], it was not surprising that we demonstrated that the variability in duration of follow-up is associated with variability in the reported outcome between studies. Finally, we also identified that the variability in PD-L1 expression is an additional variable that contributed to the demonstrated heterogeneity [36].

On the other hand, there were also some limitations. First, in several pooled effect estimates, there were significant between trials heterogeneity. That may have had its impact on the precise estimate of the benefit, however, we extensively investigated such heterogeneity and we have been able to identify its potential sources. Second, while we analyzed the pooled effects irrespective of the CPI used, it would have been inappropriate to compare benefits according to different agent agents while there have never been head-to-head comparative trials.

The current met-analysis quantified the clinical benefit of CPIs used in the first-line setting for patients with advanced NSCLC without targetable therapies. Although employing such approach represents a paradigm shift in the management of such patients, currently, CPIs use is associated with a significant high cost. In a recent review, Aquiar et al. analyzed the cost-effectiveness of immune CPIs in NSCLC [37]. In patients with squamous histology, the incremental Quality-Adjusted Life Years (QALY) of using nivolumab was 0.23 , while the incremental cost-effectiveness ratio (ICER) was US $\$ 128,000$. Using a PD-L1 expression cutoff value had minimal effect improved incremental QALY. For patients with nonsquamous histology, the incremental QALY of nivolumab was 0.12 and the ICER was US $\$ 121,000$. All patients with PD-L1 of $\geq 1$, pembrolizumab use was associated with an incremental QALY of 0.13 and an ICER was US $\$ 116,000$. Considering such data and the fact that PD-L1 expression may not be an optimal predictor, there is a dear need for additional biomarker(s) that would allow better selection of patients to offset such high cost.

\section{References}

1. Bray F, Ferlay J, Soerjomataram I, Siegel RL, Torre LA, (2018) Global cancer statistics 2018: GLOBOCAN estimates of incidence and mortality worldwide for 36 cancers in 185 countries. CA Cancer J Clin 68: 394-424. 
Citation: Ibrahim EM, Refae AA, Bayer AM, Al-Masri OA, Eldahna WM, et al. Checkpoint Inhibitors in the First-Line Setting in Advanced Non-Small Cell Lung Cancer: A Meta-AnalysisJ Cancer Sci. 2019;6(1): 14

2. Lisberg A, Garon EB (2019) Does Platinum-Based Chemotherapy Still Have a Role in First-Line Treatment of Advanced Non-Small-Cell Lung Cancer? J Clin Oncol 37: 529-536.

3. Lee CK, Man J, Lord S, Links M, Gebski V, et al. (2017) Checkpoint Inhibitors in Metastatic EGFR-Mutated Non-Small Cell Lung Cancer-A Meta-Analysis. J Thorac Oncol 12: 403-407.

4. Crequit $P$, Chaimani A, Yavchitz A, Attiche N, Cadranel J, et al. (2017) Comparative efficacy and safety of second-line treatments for advanced non-small cell lung cancer with wild-type or unknown status for epidermal growth factor receptor: a systematic review and network meta-analysis. BMC medicine 15: 193.

5. Ramos-Esquivel A, van der Laat A, Rojas-Vigott R, Juarez M, CorralesRodriguez L (2017) Anti-PD-1/anti-PD-L1 immunotherapy versus docetaxe for previously treated advanced non-small cell lung cancer: a systematic review and meta-analysis of randomised clinical trials. ESMO open 2 : e000236.

6. Ryu R, Ward KE (2018) Atezolizumab for the First-Line Treatment of Nonsmall Cell Lung Cancer (NSCLC): Current Status and Future Prospects. Front Oncol 8: 277

7. Tierney JF, Stewart LA, Ghersi D, Burdett S, Sydes MR (2007) Practical methods for incorporating summary time-to-event data into meta-analysis. Trials 8: 16.

8. Parmar MK, Torri V, Stewart L (1998) Extracting summary statistics to perform meta-analyses of the published literature for survival endpoints. Stat Med 17 2815-2834.

9. Higgins JP, Thompson SG (2002) Quantifying heterogeneity in a metaanalysis. Stat Med 21: 1539-1558.

10. Higgins JP, Thompson SG, Deeks JJ, Altman DG (2003) Measuring inconsistency in meta-analyses. BMJ 327: 557-560.

11. DerSimonian R, Laird N (1986) Meta-analysis in clinical trials. Control Clin Trials 7: 177-188.

12. Donders AR, van der Heijden GJ, Stijnen T, Moons KG (2006) Review: gentle introduction to imputation of missing values. J Clin Epidemiol 59: 1087 1091.

13. Egger M, Davey Smith G, Schneider M, Minder C (1997) Bias in metaanalysis detected by a simple, graphical test. BMJ 315: 629-634.

14. Orwin RG (1983) A Fail-Safe N for Effect Size in Meta-Analysis. J Edu Statistics 8: 157-159.

15. Duval S, Tweedie R (2000) Trim and fill: A simple funnel-plot-based method of testing and adjusting for publication bias in meta-analysis. Biometrics 56 : $455-463$

16. Carbone DP, Reck M, Paz-Ares L, Creelan B, Horn L, et al. (2017) First-Line Nivolumab in Stage IV or Recurrent Non-Small-Cell Lung Cancer. N Engl J Med 376: 2415-2426.

17. Cappuzzo F, Mekhail T, Zer A, Reinmuth N, Sadiq A, et al. (2018) LBA53IMpower130: Progression-free survival (PFS) and safety analysis from a randomised phase III study of carboplatin + nab-paclitaxel $(\mathrm{CnP})$ with or without atezolizumab (atezo) as first-line (1L) therapy in advanced nonsquamous NSCLC. Ann Oncol 29.

18. Socinski MA, Koynov KD, Berard H, Hughes BGM, Yu W, et al. (2018) LBA65IMpower131: Progression-free survival (PFS) and overall survival (OS) analysis of a randomised phase III study of atezolizumab + carboplatin + paclitaxel or nab-paclitaxel vs carboplatin + nab-paclitaxel in $1 \mathrm{~L}$ advanced squamous NSCLC. Ann Oncol 29.

19. Langer CJ, Gadgeel SM, Borghaei H, Papadimitrakopoulou VA, Patnaik A et al. (2016) Carboplatin and pemetrexed with or without pembrolizumab fo advanced, non-squamous non-small-cell lung cancer: a randomised, phase 2 cohort of the open-label KEYNOTE-021 study. Lancet Oncol 17: 1497-1508.

20. Gandhi L, Rodriguez-Abreu D, Gadgeel S, Esteban E, Felip E, et al. (2018) Pembrolizumab plus Chemotherapy in Metastatic Non-Small-Cell Lung Cancer. N Eng J Med 378: 2078-2092.
21. Paz-Ares L, Luft A, Vicente D, Tafreshi A, Gumus M, et al. (2018) Pembrolizumab plus Chemotherapy for Squamous Non-Small-Cell Lung Cancer. N Eng J Med 379: 2040-2051.

22. Rizvi NA, Vicente D, Moiseyenko V, Antonia SJ, Le Moulec S, et al. (2018) LBA6Durvalumab with or without tremelimumab vs platinum-based chemotherapy as first-line treatment for metastatic non-small cell lung cancer: MYSTIC. Ann Oncol 29

23. Reck M, Rodriguez-Abreu D, Robinson AG, Hui R, Csoszi T, et al. (2016) Pembrolizumab versus Chemotherapy for PD-L1-Positive Non-Small-Cell Lung Cancer. N Eng J Med 375: 1823-1833.

24. Reck M, Rodriguez-Abreu D, Robinson AG, Hui R, Csoszi T, et al. (2019) Updated Analysis of KEYNOTE-024: Pembrolizumab Versus Platinum-Based Chemotherapy for Advanced Non-Small-Cell Lung Cancer With PD-L1 Tumor Proportion Score of 50\% or Greater. J Clin Oncol 37: 537-546.

25. Barlesi F, Seneviratne LC, Baldini E, Watanabe S, Goto K, et al. (2018) LBA54IMpower132: Efficacy of atezolizumab (atezo) + carboplatin (carbo)/ cisplatin (cis) + pemetrexed (pem) as $1 \mathrm{~L}$ treatment in key subgroups with stage IV non-squamous non-small cell lung cancer (NSCLC). Ann Onco 29.

26. Socinski MA, Jotte RM, Cappuzzo F, Orlandi F, Stroyakovskiy D, et al. (2018) Atezolizumab for First-Line Treatment of Metastatic Nonsquamous NSCLC. N Eng J Med 378: 2288-2301.

27. Hellmann MD, Ciuleanu TE, Pluzanski A, Lee JS, Otterson GA, et al. (2018) Nivolumab plus Ipilimumab in Lung Cancer with a High Tumor Mutational Burden. N Eng J Med 378: 2093-2104.

28. Mok TSK, Wu YL, Kudaba I, Kowalski DM, Cho BC, et al. (2019) Pembrolizumab versus chemotherapy for previously untreated, PD-L1expressing, locally advanced or metastatic non-small-cell lung cancer (KEYNOTE-042): a randomised, open-label, controlled, phase 3 trial. Lancet 393: $1819-1830$.

29. Leighl NB, Hellmann MD, Hui R, Carcereny E, Felip E, et al. (2019) Pembrolizumab in patients with advanced non-small-cell lung cance (KEYNOTE-001): 3-year results from an open-label, phase 1 study. Lancet Respir Med 7: 347-357.

30. Borghaei H, Paz-Ares L, Horn L, Spigel DR, Steins M, et al. (2015) Nivolumab versus Docetaxel in Advanced Nonsquamous Non-Small-Cell Lung Cancer. N Eng J Med 373: 1627-1639.

31. Rittmeyer A, Barlesi F, Waterkamp D, Park K, Ciardiello F, et al. (2017) Atezolizumab versus docetaxel in patients with previously treated nonsmall-cell lung cancer (OAK): a phase 3, open-label, multicentre randomised controlled trial. Lancet 389: 255-265.

32. Le DT, Uram JN, Wang H, Bartlett BR, Kemberling H, et al. (2015) PD-1 blockade in tumors with mismatch-repair deficiency. N Eng J Med 372: 25092520.

33. El-Osta H, Jafri S (2019) Predictors for clinical benefit of immune checkpoint inhibitors in advanced non-small-cell lung cancer: a meta-analysis. Immunotherapy 11: 189-199.

34. Lee KWC, Lord SJ, Kasherman L, Marschner I, Stockler M, et al. (2019) The impact of smoking on the effectiveness of immune checkpoint inhibitors - a systematic review and meta-analysis. Acta Oncol 25: 1-5.

35. Hackshaw A (2008) Small studies: strengths and limitations. Eur Respir J 32 $1141-1143$

36. Rangachari D, Costa DB (2019) From Hope to Reality: Durable Overall Survival With Immune Checkpoint Inhibitors for Advanced Lung Cancer. J Clin Oncol 37: 2511-2513

37. Aguiar P Jr, Perry LA, Lopes GL Jr (2016) Cost-effectiveness of immune checkpoint inhibitors in NSCLC according to PD-L1 expression. Lung Cancer Manag 5: 119-122. 